\title{
Oxidative Degradation and Detoxification of Chlorpyrifos by Ultrasonic and Ozone Treatments
}

\author{
Sarunya Pengphol ${ }^{1,2}$, Jamnong Uthaibutra ${ }^{2,3}$, Orn-anong Arquero ${ }^{2,4}$, Nakao Nomura ${ }^{5} \&$ Kanda Whangchai $^{2,3}$ \\ ${ }^{1}$ Postharvest Technology Research Institute, Graduate School, Chiang Mai University, Chiang Mai, Thailand \\ ${ }^{2}$ Postharvest Technology Innovation Center, Commission on Higher Education, Bangkok, Thailand \\ ${ }^{3}$ Department of Biology, Faculty of Science, Chiang Mai University, Chiang Mai, Thailand \\ ${ }^{4}$ Department of Chemistry, Faculty of Science, Chiang Mai University, Chiang Mai, Thailand \\ ${ }^{5}$ Graduate School of Life and Environmental Science, University of Tsukuba, Tennodai, Tsukuba, lbaraki, Japan \\ Correspondence: Kanda Whangchai, Department of Biology, Faculty of Science, Chiang Mai University, Chiang \\ Mai 50200, Thailand. Tel: 66-5394-3346-60 Ext.1204. E-mail: kanda.w@cmu.ac.th
}

Received: May 3, 2012 Accepted: May 22, 2012 Online Published: July 11, 2012

doi:10.5539/jas.v4n8p164

URL: http://dx.doi.org/10.5539/jas.v4n8p164

\begin{abstract}
Chlorpyrifos is an organophosphate pesticide, widely used on fruit and vegetable crops. Here, we report on the oxidative degradation of standard chlorpyrifos by individual and combined effects of ultrasonic irradiation (US) and ozone $\left(\mathrm{O}_{3}\right)$. A standard chlorpyrifos solution $\left(1 \mathrm{mg} \mathrm{L}^{-1}\right)$ was treated with $1 \mathrm{MHz} \mathrm{US}, \mathrm{O}_{3}$ and its combination $\left(\mathrm{US} / \mathrm{O}_{3}\right)$ for $0,10,20,30,40,50$ and $60 \mathrm{~min}$. Reduction of residual chlorpyrifos was determined by gas chromatography with flame photometric detection (GC-FPD) while ion chromatography (IC) was used to determine the concentration of anions as major degradation products. US $/ \mathrm{O}_{3}$ combined treatment had a synergistic effect in reducing chlorpyrifos concentrations, with the highest rate of degradation occurring within the first $10 \mathrm{~min}$. Moreover, chloride, nitrate and sulphate anion concentrations obtained from chlorpyrifos treated with $\mathrm{US} / \mathrm{O}_{3}$ combination, were significantly higher, compared to those treated with ultrasonic irradiation or ozone alone. A sharp decrease in $\mathrm{pH}$ from 7.46 to 4.49 was also observed for the combined treatment. The degradation pathway of chlopyrifos, after treatment, was confirmed by gas chromatography mass spectrometry (GC-MS). All treatments resulted in similar main fragment ions at $\mathrm{m} / \mathrm{z} 351,314,286,258,197$ and 97 . The lethal concentration $\left(\mathrm{LC}_{50}\right)$, over a series $(0-100) \mathrm{mg} \mathrm{L}^{-1}$ of standard chlorpyrifos solutions, was estimated and compared to the treated chlorpyrifos. All the treatments directly detoxified chlorpyrifos with $\mathrm{LC}_{50}$ values against brine shrimps (Artemia salina L.) of $10.21,103.54$ and $234.09 \mathrm{mg} \mathrm{L}^{-1}$ for $\mathrm{US}, \mathrm{O}_{3}$ and $\mathrm{US} / \mathrm{O}_{3}$ treated chlorpyrifos solutions, respectively. The brine shrimp test showed highest toxicity in standard chlorpyrifos with an $\mathrm{LC}_{50}$ value of $7.22 \mathrm{mg} \mathrm{L}^{-1}$.
\end{abstract}

Keywords: chlorpyrifos, detoxification, oxidative degradation, ozone, ultrasonic

\section{Introduction}

Chlorpyrifos is one of the most widely used organophosphate pesticides in agriculture. The intrinsic toxic properties of pesticides allow them to control agricultural insect pests. The annual average global use of chlorpyrifos between 2002 and 2006 was 25 million $\mathrm{kg}$ active ingredient, of which 98.5\% was used for agricultural purposes. Continuous and excessive use of chlorpyrifos has already led to widespread environmental contamination in many countries. This insecticide has been detected in marine, sediments, streams, sumps, sloughs, rivers, urban storm drains, freshwater lakes, groundwater, fog, rain and air (Whitacre, 2012). Nowadays, consumers and importers demand residue-free products. Being moderately toxic, there are significant concerns about the potential risks posed by chlorpyrifos to humans and the environment. It is therefore of significance to evaluate potential methods of reducing pesticide residue on water and food products.

Ultrasonic irradiation (US) technology effectively reduces a variety of organic and inorganic contaminants (Weavers et al., 1998) and its acoustic cavitations generate many hot spots, with locally high temperatures and pressures, that cause sonolysis of water molecules. Consequently, ${ }^{\bullet} \mathrm{H},{ }^{\bullet} \mathrm{OH},{ }^{\bullet} \mathrm{OOH}$ radical species are formed, which directly destroy chemicals in aqueous solution. Wang et al. (2006) reported that methyl parathion is degraded by $40 \mathrm{kHz}$ ultrasonic irradiation. Moreover, ultrasonic irradiation at $640 \mathrm{kHz}$ effectively and rapidly 
degrades 2-methylisoborneol (MIB) and geosmin (GSM), with ${ }^{\bullet} \mathrm{OH}$ scavengers playing a major role in chemical degradation (Song \& O'Shea, 2007).

Use of ozone $\left(\mathrm{O}_{3}\right)$ is a promising method to reduce chlorpyrifos residues in fresh lychee fruits (Whangchai et al., 2011). In addition, Inan et al. (2007) found that after $60 \mathrm{~min}$ of ozone exposure, aflatoxin $\mathrm{B}_{1}$ content is reduced in flaked and chopped red peppers (Capsicum annuum) by 80 and $93 \%$, at a rate of 33 and $66 \mathrm{mg} \mathrm{L}^{-1}$, respectively. $\mathrm{Wu}$ et al. (2007) demonstrated that using dissolved ozone $\left(1.4 \mathrm{mg} \mathrm{L}^{-1}\right)$ for $60 \mathrm{~min}$ effectively reduces methyl-parathion, cypermethrin, parathion and diazinon in aqueous solution.

The combined process of ultrasonication and ozonation offers several advantages over the individual process. The main advantage is the increased mass transfer of ozone from the gas phase to the bulk solution to react with substrate by mechanical effects of ultrasound. Cavitation bubbles from ultrasonication likewise can more readily induce $\mathrm{O}_{3}$ decomposition under mild conditions yielding molecular $\mathrm{O}_{2}$ and triplet atomic oxygen, ${ }^{\circ} \mathrm{O}\left({ }^{3} \mathrm{P}\right)(\mathrm{Pang}$ et al., 2011). In the combined system, ultrasonication and ozonation were believed to enhance each other in the oxidation of organic pollutants. $\mathrm{US} / \mathrm{O}_{3}$ combined process was employed to pretreat heterocyclic pesticide wastewater for increasing biodegradability and reducing biological toxicity (Xiong et al., 2011). Moreover, the combined operation effectively renders synergistic effect of ozone and ultrasonic radiation on degradation of chitosan enhancing the production of hydroxyl radical generated by the radiolysis of ozone in the presence of ultrasonic radiation (Yue et al., 2008). The purpose of the research, reported below, was to investigate the combined effects of ultrasonic irradiation on the degradation and detoxification of chlorpyrifos.

\section{Materials and Methods}

Reference standard chlorpyrifos was purchased from Sigma-Aldrich Laborchemikalien GmbH (Stienheim, Germany) with $99.9 \%$ purity. The chlorpyrifos structure is shown in Figure 1. Chlorpyrifos stock solution (1000 $\mathrm{mg} \mathrm{L}^{-1}$ ) was prepared by dissolving standard chlorpyrifos in $99.8 \%$ acetone. The solution was diluted with distilled water to the appropriate concentrations.<smiles>CCOP(=S)(OCC)Oc1nc(Cl)c(Cl)cc1Cl</smiles>

Figure 1. Structure of chlorpyrifos

The ultrasonic device with an input power of $3 \mathrm{~W}$ was supplied by Honda Electronics Company (Toyohashi, Aichi, Japan), equipped with a $1-\mathrm{MHz}$ ultrasonic transducer. A $25-\mathrm{mL}$ chlorpyrifos solution was subjected to sonication in a $10-\mathrm{cm}$ diameter polyethylene cylinder reactor fitted with a polyethylene window facing the transducer.

Ozone gas, produced by an ozone generator (Ozonizer, Sky zone model S05AE, Thailand), with a flow rate of $25 \mathrm{~mL} \mathrm{~min}^{-1}$, was bubbled into the chlorpyrifos solution directly. Dissolved ozone was determined by the indigo colorimetric method (Eaton et al., 2005).

\subsection{Reduction of Standard Chlorpyrifos Solution by Ultrasonic and Ozone Treatments}

A standard chlorpyrifos solution $\left(25 \mathrm{~mL}, 1 \mathrm{mg} \mathrm{L}^{-1}\right)$ was prepared then poured inside the ultrasonic reactor and irradiated at $1 \mathrm{MHz}$. Ozone gas was bubbled through the chlorpyrifos solution at $200 \mathrm{mg} \mathrm{L}^{-1}$. Standard solutions were exposed to individual and combined ultrasonic radiation and ozone treatment. Samples were taken out at 10-min intervals for $1 \mathrm{~h}$. Three replicates of chlorpyrifos samples were analyzed. Chlorpyrifos concentrations were determined by gas chromatography. The analysis was performed in Agilent Technologies (Wilmington, DE) model 6890 gas chromatograph equipped with a flame photometric detector (GC-FPD). The GC column was a fused silica capillary column HP-5, 5\% phenylmethylsiloxane, with the dimensions of $30 \mathrm{~m} \times 0.32 \mathrm{~mm}$ i.d. and a $0.25 \mu \mathrm{m}$ film thickness (Agilent Technologies). The temperature was programmed to increase at $10^{\circ} \mathrm{C}$ $\mathrm{min}^{-1}$ from an initial $100^{\circ} \mathrm{C}$ to $200^{\circ} \mathrm{C}$ and then at $4^{\circ} \mathrm{C} \mathrm{min}^{-1}$ increase to the final temperature of $220^{\circ} \mathrm{C}$. A purified helium carrier gas was used at a flow rate of $3.6 \mathrm{~mL} \mathrm{~min}^{-1}$. The detector temperature was at $250^{\circ} \mathrm{C}$. Sample solution $(1.0 \mu \mathrm{L})$ was injected in splitless mode. Quantification of chlorpyrifos was performed, using a chlorpyrifos standard as reference. 


\subsection{Oxidative Degradation and Detoxification of Treated Chlorpyrifos by Ultrasonic and Ozone Treatments}

The $\mathrm{pH}$ and concentrations of anions such as chloride, nitrate, sulphate and phosphate of ultrasonicated and ozonated chlorpyrifos solutions were determined. Ions, released from the decomposition of chlorpyrifos, were analyzed at $60 \mathrm{~min}$ by ion chromatography (IC). The amount of these ions corresponded to degradation of chlorpyrifos in this study. The analysis was performed, using an ion chromatograph equipped with a Metrosep A Supp 5 250/4.0. Eluent composition was A Supp5 eluent $3.2 \mathrm{mM} \mathrm{Na}_{2} \mathrm{CO}_{3}$ and $1.0 \mathrm{mM} \mathrm{NaHCO}$. Samples were filtered by syringe filters of size $13 \mathrm{~mm}, 0.45 \mu \mathrm{m}\left(\right.$ Vertical $\left.^{\circledR}\right)$. A $10.0 \mu \mathrm{L}$ sample was automatically injected in conductivity mode, and the quantification of chlorpyrifos was carried out using calibration curves with external standards at a flow rate of $0.70 \mathrm{~mL} \mathrm{~min}{ }^{-1}$, pressure $12.71 \mathrm{MP}$ and $28 \mathrm{~min}$ recording time.

An Agilent Technologies (Wilmington, DE) model 6850 gas chromatograph equipped with a mass spectrometer (GC-MS) was used to analyze oxidative degradation of chlorpyrifos. The GC column was a fused silica capillary column HP-5MS, 5\% phenylmethylsiloxane, with the dimensions of $30 \mathrm{~m} \times 0.25 \mu \mathrm{m}$ i.d. and a $250 \mu \mathrm{m}$ film thickness (Agilent Technologies). The temperature was programmed to increase at $20^{\circ} \mathrm{C} \mathrm{min}{ }^{-1}$ from an initial $100^{\circ} \mathrm{C}$ to $200^{\circ} \mathrm{C}$ and then at $4^{\circ} \mathrm{C} \min ^{-1}$ increase to the final temperature of $220^{\circ} \mathrm{C}$ at 2 min holding time. A purified helium carrier gas was used at a constant flow. The MS was operated in electron impact (EI) ionization time-of-flight mode (TOF-MS) at an EM voltage of 1811.8 volts (injection volume $1.0 \mu \mathrm{L}$ in splitless mode). The total ion current (TIC) chromatograms were recorded between $50-400 \mathrm{~m} / \mathrm{z}$, at a rate of 37 scans per second. EI mass spectrum database searches were carried out in a mass spectral library (National Institute for Standard Technology (NIST) search program version 1.5, Gaithersburg, MD, USA).

Toxicity estimations were an important tool to test for the treatment efficiency. Diluted solutions with $0,0.1$, 10.0 and $100 \mathrm{mg} \mathrm{L}^{-1}$ chlorpyrifos were prepared in laboratory marine water for US, $\mathrm{O}_{3}$ and $\mathrm{US} / \mathrm{O}_{3}$ treatment. Five sets of experiment were done for each concentration per treatment at $25-30^{\circ} \mathrm{C}$. Ten brine shrimps nauplii were placed in each vial containing $5 \mathrm{~mL}$ of treated chlorpyrifos solution. Mortality of nauplii was checked every $6 \mathrm{~h}$ eventually after $72 \mathrm{~h}$ of incubation. The percent mortality was determined $24 \mathrm{~h}$ after application. Probit analysis in SPSS version 17 was used for the calculation of $\mathrm{LC}_{50}$ values.

\subsection{Statistical Analysis}

All experiments were evaluated with a regression procedure, using the SPSS version 17, while the differences among various treatments were performed using a one-way analysis of variance followed by Duncan's New Multiple Range test $(\mathrm{p}<0.05)$.

\section{Results and Discussions}

\subsection{Reduction of Standard Chlorpyrifos Solution by Ultrasonic and Ozone Treatments}

The concentration $\left(1 \mathrm{mg} \mathrm{L}^{-1}\right)$ of standard chlorpyrifos, treated with US, $\mathrm{O}_{3}$ and $\mathrm{US} / \mathrm{O}_{3}$ in combination, decreased with increasing exposure time. During the first $10 \mathrm{~min}$ of treatments, chlorpyrifos concentration was significantly reduced, compared with the control. The US/ $\mathrm{O}_{3}$ combination treatment, applied simultaneously for 60 min, was the most effective at reducing chlorpyrifos concentration to $0.17 \mathrm{mg} \mathrm{L}^{-1}$. Therefore, the $\mathrm{US} / \mathrm{O}_{3}$ combination decreased chlorpyrifos concentration, twice as much as that accomplished by $\mathrm{O}_{3}$ alone $\left(0.33 \mathrm{mg} \mathrm{L}^{-1}\right)$ (Figure 2). Plots of $\ln \left(\mathrm{C}_{t} / \mathrm{C}_{0}\right)$ versus contact time ( $\mathrm{t}$ ) are shown in Figure 3. First-order rate constants, $k$ of chlorpyrifos under different treatments are summarized in Table 1. Rate constants varied from $0.30 \times 10^{-2}$ to $3.51 \times 10^{-2} \mathrm{~min}^{-1}$ with $\mathrm{US} / \mathrm{O}_{3}$ combined treatment's $k$ being the largest. A larger value of $k$ signifies that chlorpyrifos degradation is more rapid in the combined treatment. Similarly, Ince \& Tezcanli (2001) observed that the US/ $\mathrm{O}_{3}$ combined treatment achieved results twice as fast as with $\mathrm{O}_{3}$ alone, while no significant removal was observed in the control experiments with US alone. It is possible that oxidation plays a similar role in both ozonolysis and sonolysis pathways, and some free-radical pathways present during ozonation, are similar to those of sonolysis (Schramm \& Hua, 2001). The observed synergy was attributed to enhanced ozone diffusion (promotes more rapid electrophilic and radical reaction rates) and enhanced hydroxyl radical formation of some intermediate products of oxidation (Tezcanli \& Ince, 2004). The US/ $\mathrm{O}_{3}$ combination produced a myriad of tiny air bubbles by the cavitation effect of ultrasound, allowing most ozone to enter the liquid phase or react on the gas or liquid interface. The physicochemical properties of the $\mathrm{US} / \mathrm{O}_{3}$ combination enhanced the rate of direct reactions and hydroxyl radical's oxidation of intermediate products (Cui et al., 2011). In addition, rapid degradation of organic contaminants, using ozone and ultrasonic irradiation $(20 \mathrm{kHz})$, resulted in an increase of hydroxyl radicals (Weavers et al., 1998). The combined electrochemical cell under ultrasonic irradiation and ozone treatment with simultaneous ultrasonic irradiation led to virtually complete consumption of 1,3-dinitrobenzene, 2,4-dinitrotoluene within a short time (Abramov et al., 2007). 
Table 1. The first-order kinetic model fitted to the chlorpyrifos degradation

\begin{tabular}{llcc}
\hline Treatment & Regression equation & $\mathbf{R}^{\mathbf{2}}$ & $\boldsymbol{k}\left(\mathbf{m i n}^{-1}\right)$ \\
\hline Control & $\ln \left(\mathrm{C}_{\mathrm{t}} / \mathrm{C}_{0}\right)=-0.0030 \mathrm{t}$ & 0.88 & $0.30 \times 10^{-2}$ \\
$\mathbf{U S}$ & $\ln \left(\mathrm{C}_{\mathrm{t}} / \mathrm{C}_{0}\right)=-0.0237 \mathrm{t}$ & 0.96 & $2.37 \times 10^{-2}$ \\
$\mathbf{O}_{3}$ & $\ln \left(\mathrm{C}_{\mathrm{t}} / \mathrm{C}_{0}\right)=-0.0209 \mathrm{t}$ & 0.99 & $2.09 \times 10^{-2}$ \\
$\mathbf{U S}_{\mathbf{O}} \mathbf{O}_{\mathbf{3}}$ & $\ln \left(\mathrm{C}_{\mathrm{t}} / \mathrm{C}_{0}\right)=-0.0351 \mathrm{t}$ & 0.80 & $3.51 \times 10^{-2}$ \\
\hline
\end{tabular}

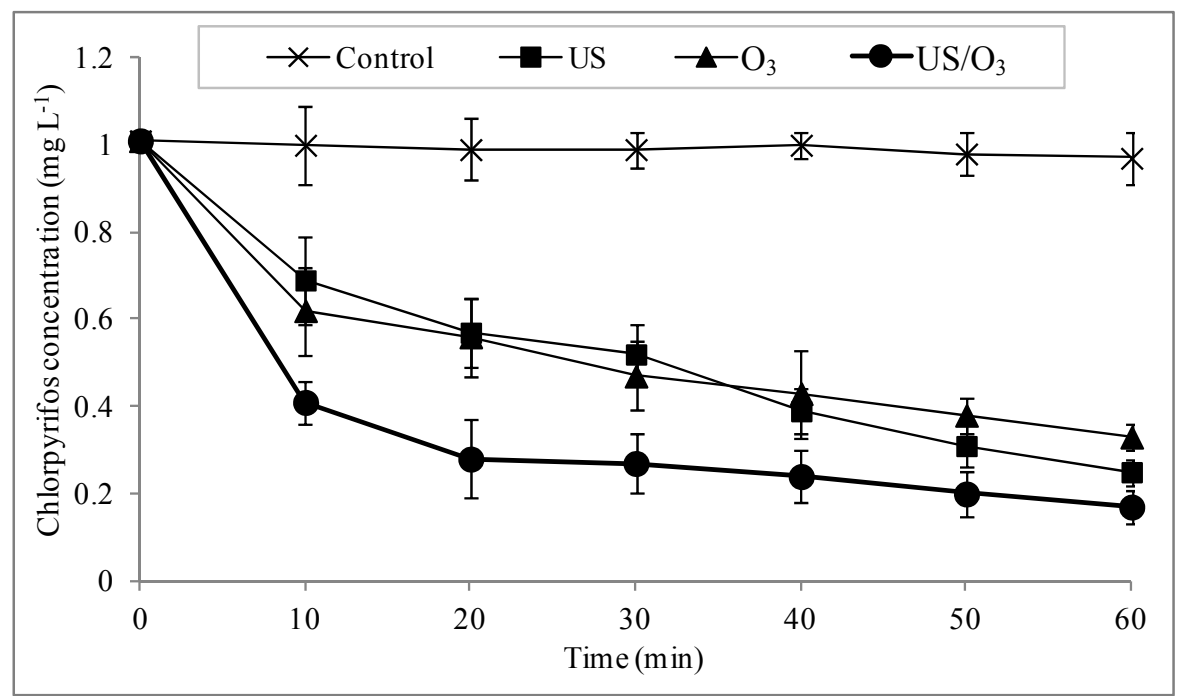

Figure 2. Chlorpyrifos concentrations after treatment with $\mathrm{US}$ and $\mathrm{O}_{3}$ showed statistically significant degradation

$(\mathrm{P}<0.05)$. The values are expressed as mean \pm S.E. of measurements made on three replicates of treatment

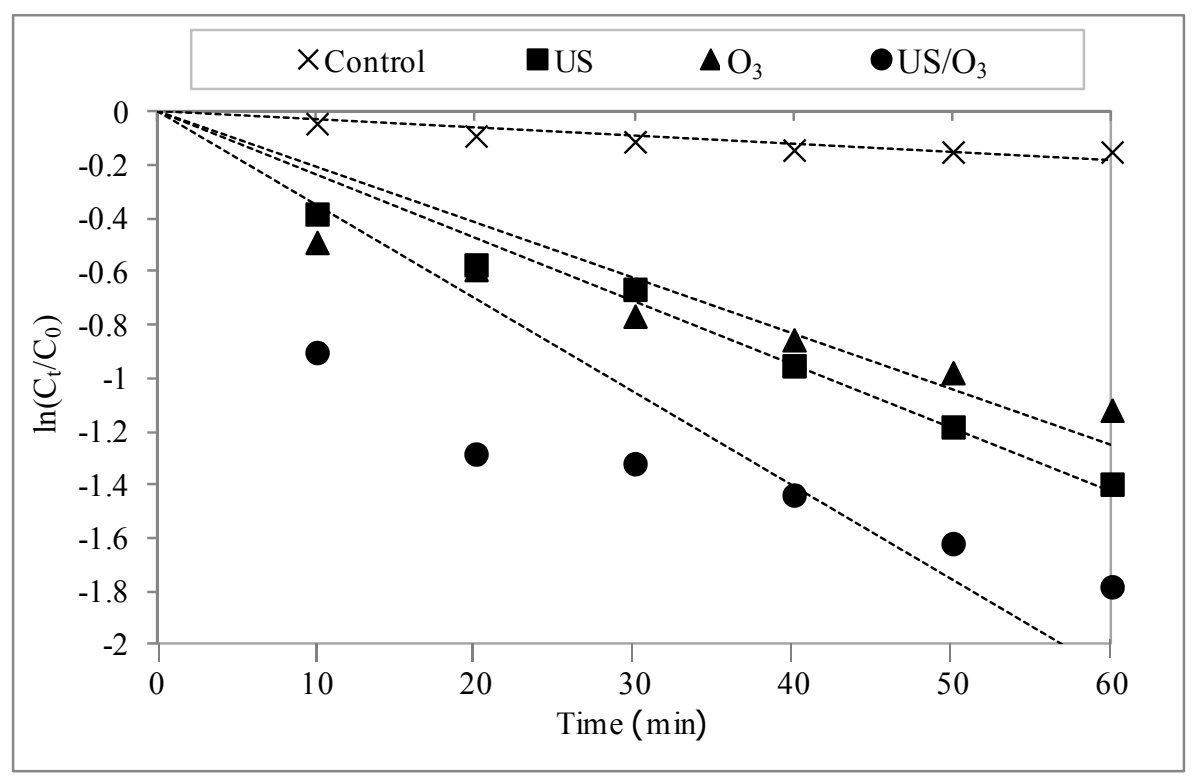

Figure 3. The degradation kinetics of chlorpyrifos under ultrasonic combined with ozone treatments

As clearly shown in US, $\mathrm{O}_{3}$ and US/O $\mathrm{O}_{3}$ combination, the longer the treatments, the greater is the reduction of chlorpyrifos concentration. Further study is needed to explain the exact oxidative degradation and detoxification of treated chlorpyrifos with ultrasonic and ozone treatment. 


\subsection{Oxidative Degradation and Detoxification of Treated Chlorpyrifos by Ultrasonic and Ozone Treatments}

Chlorpyrifos, treated with the US/O${ }_{3}$ combination, resulted in significantly increased anion concentrations, compared with the control. However, phosphate ions were not detected in any of the treated chlorpyrifos solution (data not shown). Chlorpyrifos, treated with $\mathrm{US} / \mathrm{O}_{3}$ for $60 \mathrm{~min}$, significantly $(\mathrm{P}>0.05)$ increased chloride concentration compared with all other treatments (Figure 4A). The nitrate (Figure 4B) and sulphate (Figure 4C) concentration were significantly $(\mathrm{P}>0.05)$ increased after treatment of the chlorpyrifos solution with $\mathrm{US} / \mathrm{O}_{3}$ combination for $60 \mathrm{~min}$. Therefore, anions released to indicate the chlorpyrifos decomposition. It may suggest that by Yao et al. (2010), observed during parathion degradation under ultrasonic irradiation, that sulphate concentration rapidly increased in the first $45 \mathrm{~min}$ and then stabilizes. The concentration of nitrate increased steadily and reached a concentration after $120 \mathrm{~min}$. The formation of nitrate was much slower than for other anions, possibly because of the sequential oxidation of nitrogen-containing species.
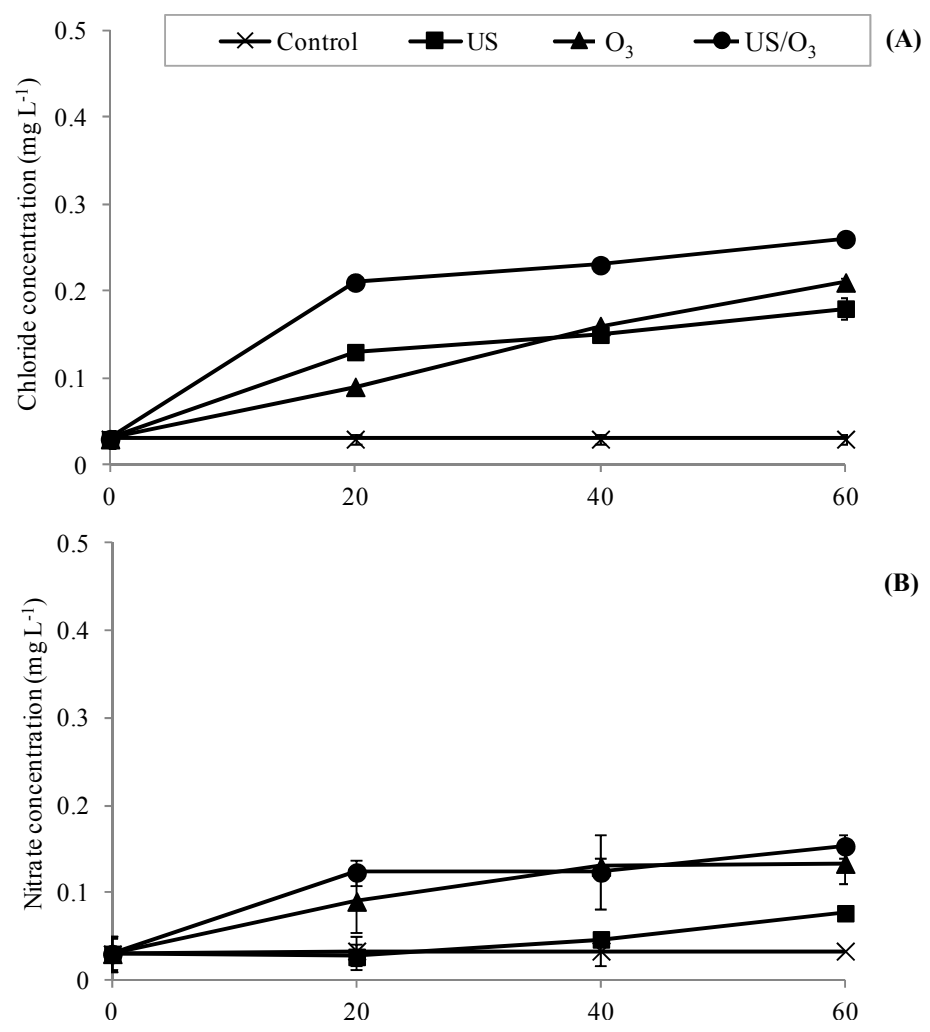

(B)

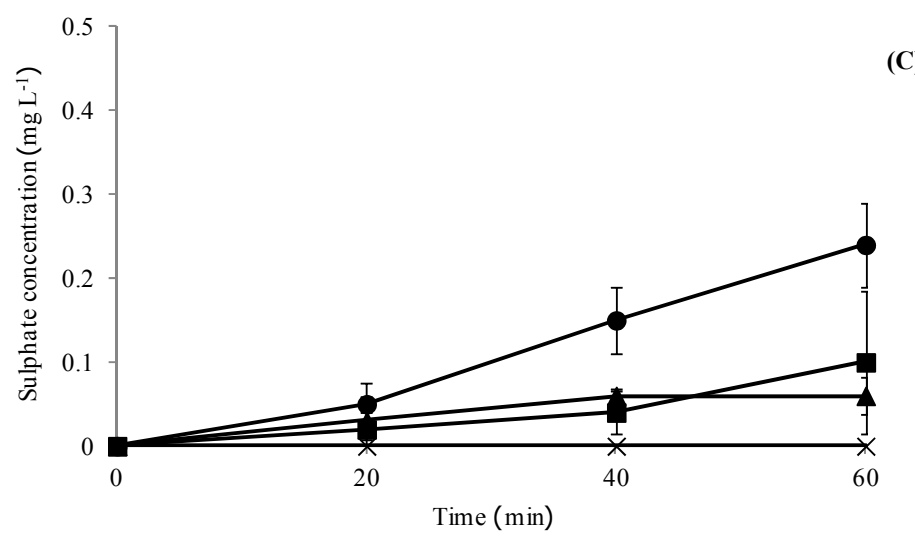

Figure 4. Chloride (A) nitrate (B) and sulphate (C) concentrations in a standard chlorpyrifos solution after application US and $\mathrm{O}_{3}$ treatments were significantly different according to the Duncan's New Multiple Range

test $(\mathrm{P}<0.05)$. The values represent mean $\pm \mathrm{S}$.E. of measurements made on three replicates of treatment

$\mathrm{pH}$ decreased in solutions, treated with $\mathrm{US}, \mathrm{O}_{3}$ and combination of $\mathrm{US} / \mathrm{O}_{3} \cdot \mathrm{pH}$ decreased with increasing contact time. Notably, the $\mathrm{pH}$ of the US/O${ }_{3}$ combination for 60 min rapidly declined from 7.46 to 4.49 (Figure 5). The pH-drop of chlorpyrifos solution might be attributed to the chlorpyrifos structure decomposed or/and released 
some acid into solution during oxidation, under US, $\mathrm{O}_{3}$ and $\mathrm{US} / \mathrm{O}_{3}$ treatments. According to Devi et al. (2009) showed that reduced substituent ${ }^{-} \mathrm{Cl}$ and ${ }^{-} \mathrm{OH}$ groups may be eliminated as $\mathrm{HCl}$ and $\mathrm{H}_{2} \mathrm{O}$. Under the effect of $\mathrm{O}_{3} /$ ultrasonic, nitro and nitroso are formed after $-\mathrm{N}=\mathrm{N}$ - bond is broken. Benzene ring is broken and oxidized into carboxylic acid. Sulfogroup breaks into sulfuric acid. So, $\mathrm{pH}$ value of the arsenazo I solution continuously drops down from 8.4 to 3.2 (Wenrong \& Haiyan, 2002). Therefore, reduced $\mathrm{pH}$ may release some acid from the chlorpyrifos solution after the oxidation, which could be confirmed by GC-MS. All treatments resulted in similar main fragment ions. Chlorpyrifos-oxon could not be determined at $\mathrm{m} / \mathrm{z} 335$. This formation is due to the result of hydroxyl radicals attack at the $-\mathrm{P}=\mathrm{S}$ bond converting it to $-\mathrm{P}=\mathrm{O}$ (oxon derivative), a primary characteristic product, formed during the oxidation of organophosphorous compounds. The $\mathrm{US} / \mathrm{O}_{3}$ combination produced the main fragment ions at $\mathrm{m} / \mathrm{z}$ 351, 314, 286, 258, 197 and 97 (Figure 6). The fragment ion at $\mathrm{m} / \mathrm{z} 351$ was from molecular ions of chlorpyrifos. The fragment ion at $\mathrm{m} / \mathrm{z} 314$ was the result of a loss of ${ }^{35} \mathrm{Cl}_{2}$ or ${ }^{37} \mathrm{Cl}$ atom from the chlorpyrifos molecular. Similarly, Meng et al. (2010) found that the mass fragment at $\mathrm{m} / \mathrm{z} 314$ was assigned to the daughter ions of chlorpyrifos, after losing a $\mathrm{Cl}$ atom during oxidation process by ozone. In addition, the fragment ions at $\mathrm{m} / \mathrm{z} 286$ and 258 were the result of the loss of two ethylenes $\left(\mathrm{C}_{2} \mathrm{H}_{4} \mathrm{~m} / \mathrm{z} 28\right)$ from the fragment ion at $\mathrm{m} / \mathrm{z} 314$. Each mass spectrum was normalized to its most intense fragment at $\mathrm{m} / \mathrm{z} 197$, possibly TCP (3,5,6-trichloro-2-pyridinol, $\mathrm{C}_{5} \mathrm{H}_{2} \mathrm{Cl}_{3} \mathrm{NO}$ ) obtained by the loss of the side chain (Mori et al., 2006). The fragment ion at $\mathrm{m} / \mathrm{z} 97$ was due to the formation of 2-hydroxy pyridine. Intermediates may react with three hydrogen radicals, eliminating all the three chloro $\left({ }^{-} \mathrm{Cl}\right)$ groups as $\mathrm{HCl}$, leading to the formation of other intermediates (Devi et al., 2009).

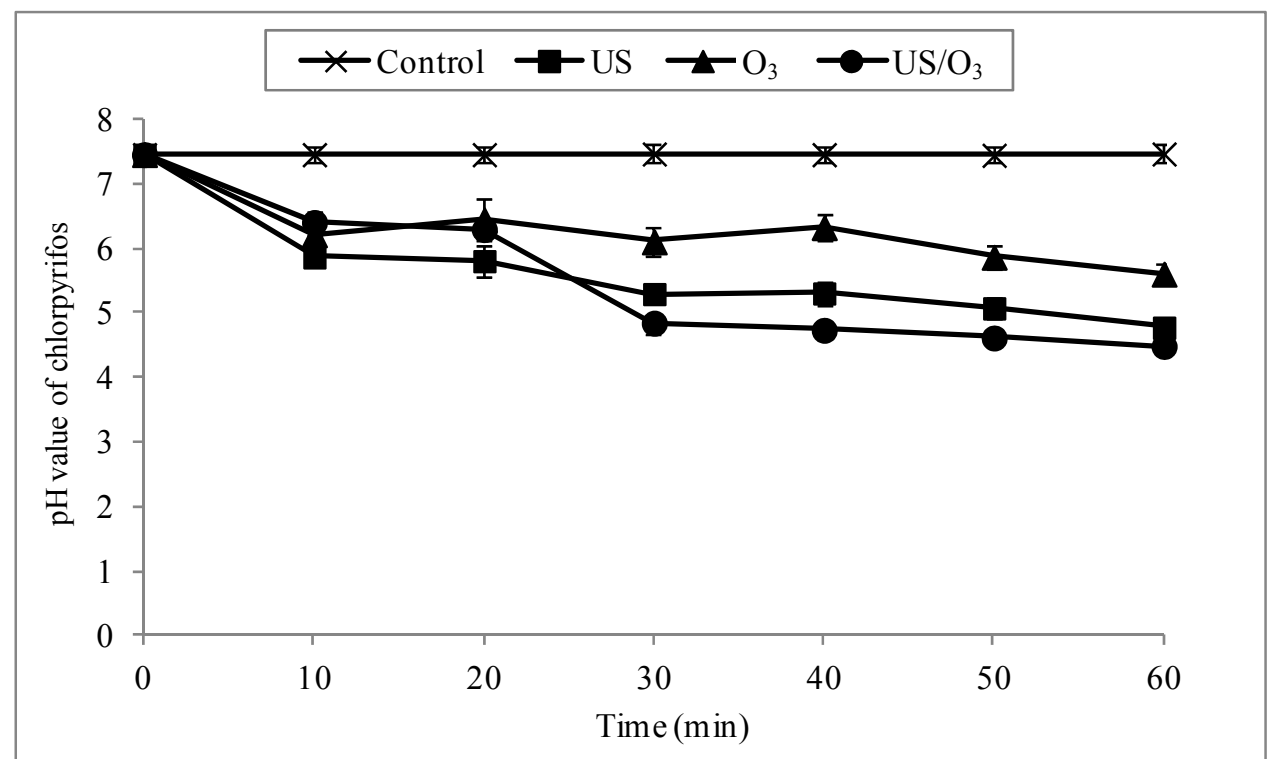

Figure 5. $\mathrm{pH}$ of standard chlorpyrifos solution after treatment with $\mathrm{US}, \mathrm{O}_{3}$ and $\mathrm{US} / \mathrm{O}_{3}$. Data are the means $\pm \mathrm{S}$.E. $(\mathrm{n}=3)$ 


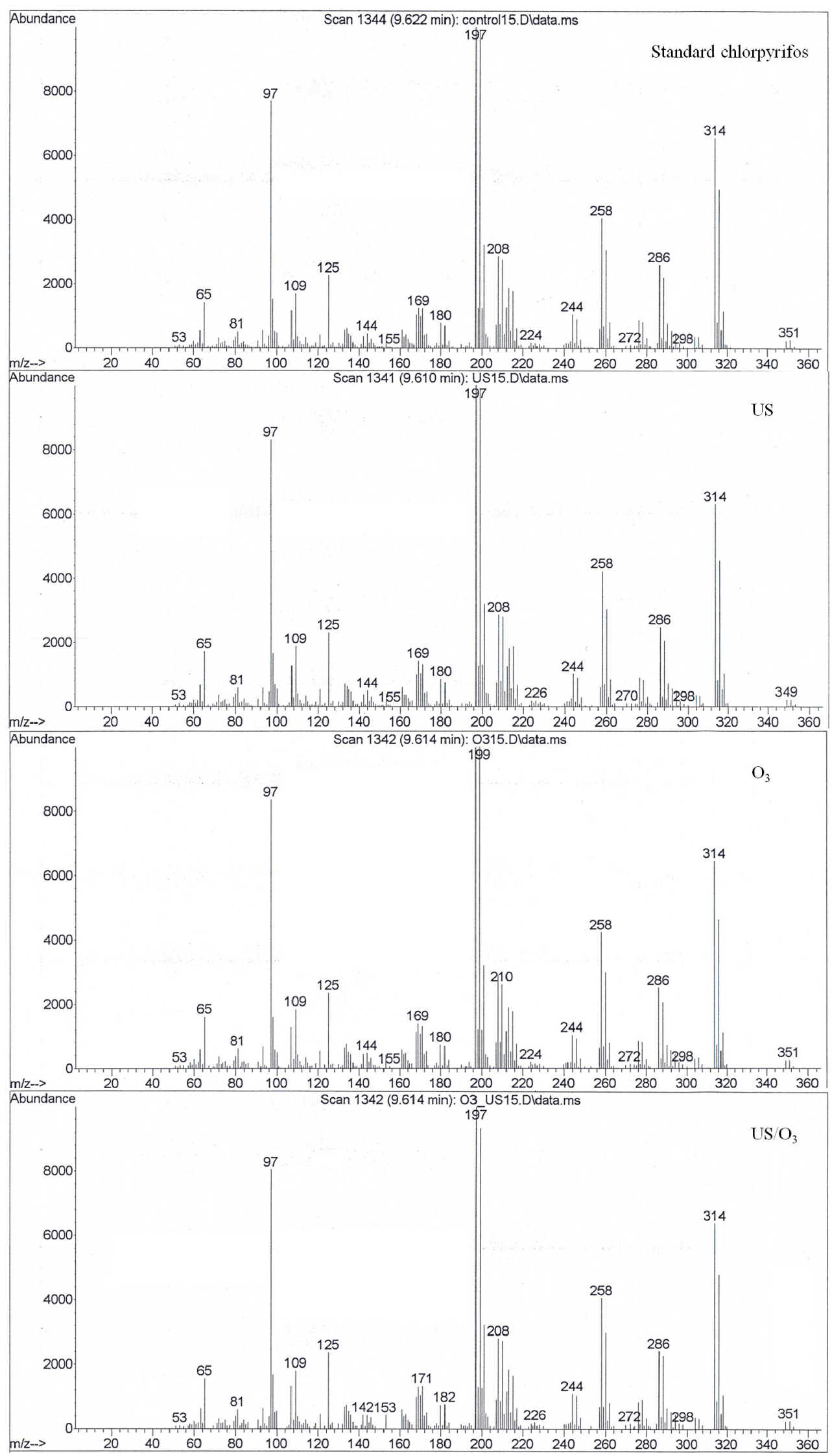

Figure 6. GC-MS spectra of chlorpyrifos after treatment with US and $\mathrm{O}_{3}$ 
Toxicity was slightly reduced after treatments as revealed by the $\mathrm{LC}_{50}$ values at $24 \mathrm{~h}$ which increased from 7.22 to $10.21 \mathrm{mg} \mathrm{L}^{-1}$. The $\mathrm{O}_{3}$ and $\mathrm{US} / \mathrm{O}_{3}$ treatments increased $\mathrm{LC}_{50}$ up to 103.54 and $234.09 \mathrm{mg} \mathrm{L}^{-1}$ respectively (Figure 7). The toxicity evaluation indicated the toxicity of chlorpyrifos decreased after US/ $\mathrm{O}_{3}$ treatment. It may chlorpyrifos concentration degraded by the combination as less toxicity than the other treatment. Tsuda et al. (1997) reported that fish contamination and other aquatic organisms by the oxidized products of diazinon and other organophosphorus pesticides in the environment were low concentration. According by Schneider et al. (2003), the reduction in Karenia brevis toxin concentration by ozone in sea water, displayed a positive correlation with the reduction of toxicity as determined by a fish (Cyprinodon variegatus) bioassay. The US/O $\mathrm{O}_{3}$ treatment improved detoxification of the tested chlorpyrifos solutions, suggesting a synergistic effect between US and $\mathrm{O}_{3}$ in improving the biodegradability of pesticides in wastewater (Xiong et al., 2011).

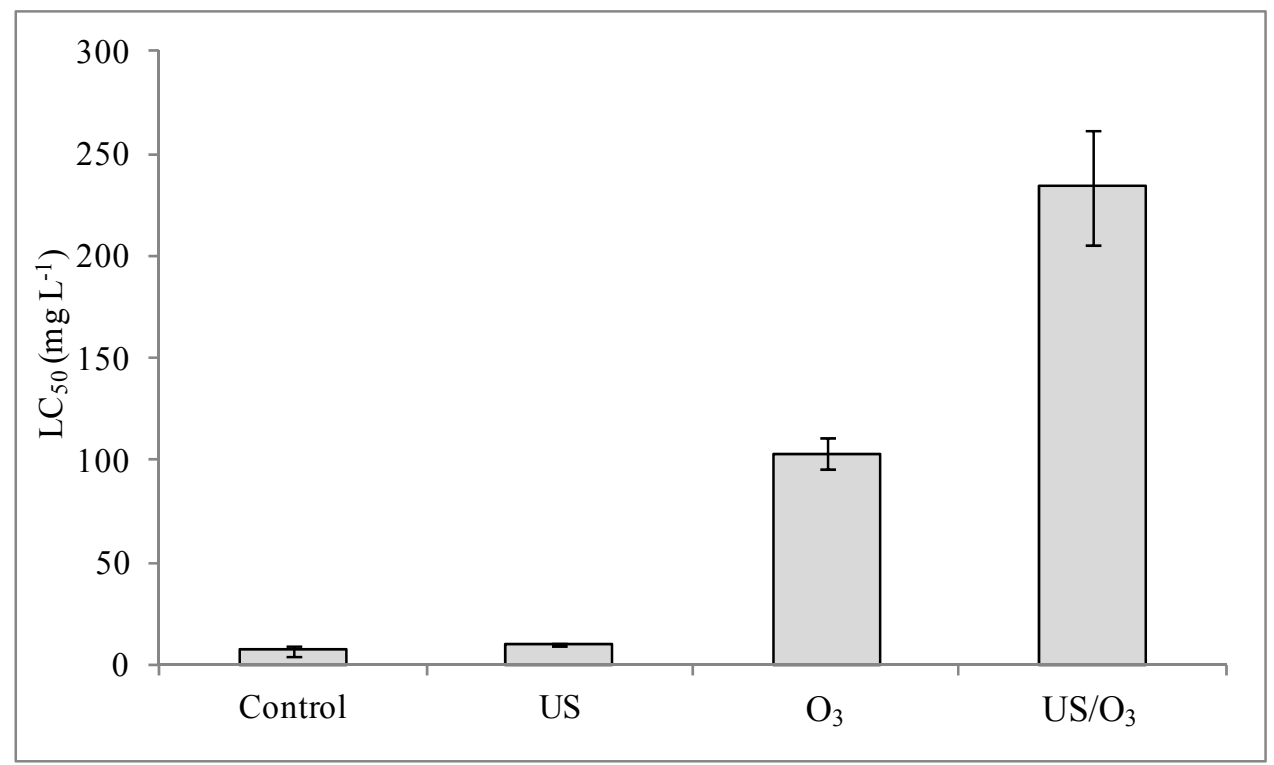

Figure 7. $\mathrm{LC}_{50}$ values (24 h) to the brine shrimp (Artemia salina $\mathrm{L}$.) toxicity of chlorpyrifos after treatment with $\mathrm{US}$ and $\mathrm{O}_{3}$.

\section{Conclusions}

US and $\mathrm{O}_{3}$, applied in combination had a synergistic effect in reducing chlorpyrifos concentration with most of the degradation occurring within the first $10 \mathrm{~min}$. Chloride, nitrate and sulphate anions released from the chlorpyrifos structure, during decomposition, might be related with the oxidation by ozone and indirect oxidation by ultrasound-generated ${ }^{\circ} \mathrm{OH}$. The $\mathrm{pH}$ of treated chlorpyrifos with $\mathrm{US} / \mathrm{O}_{3}$ treatment decreased markedly from 7.46 to 4.49 , suggesting that chlorpyrifos degradation might have release $\mathrm{HCl}$ during the process. The combined $\mathrm{US} / \mathrm{O}_{3}$ treatments significantly lowered toxicity of chlorpyrifos. The results reported here show that the combination of ultrasonic irradiation and ozone represent a potential.

\section{Acknowledgments}

The authors acknowledge financial support from Nakhon Sawan Rajabhat University (the Scholarships for the Ph.D. program) and Postharvest Technology Innovation Center, Commission on Higher Education, Bangkok. This research was conducted in Postharvest Technology Research Institute, Graduate School, Chiang Mai University which provided the laboratory facilities. The authors thank Honda Electronics Company (Toyohashi, Aichi, Japan) for ultrasonic device support.

\section{References}

Abramov V. O., Abramov, O. V., Gekhman, A. E., Kuznetsov, V. M., \& Price, G. J. (2007). Ultrasonic intensification of ozone and electrochemical destruction of 1,3-dinitrobenzene and 2,4-dinitrotoluene. Ultrasonics Sonochemistry, 13, 303-307. http://dx.doi.org/10.1016/j.ultsonch.2005.04.007

Cui, M., Jang, M., Cho, S. H., Elena, D., \& Khim, J. (2011). Enhancement in mineralization of a number of natural refractory organic compounds by the combined process of sonolysis and ozonolysis $\left(\mathrm{US} / \mathrm{O}_{3}\right)$. Ultrasonics Sonochemistry, 18, 773-780. http://dx.doi.org/10.1016/j.ultsonch.2010.11.009

Devi, L. G., Murthy, B. N., \& Kurmar, S. G. (2009). Photocatalytic activity of $\mathrm{V}^{5+}, \mathrm{Mo}^{6+}$ and $\mathrm{Th}^{4+}$ doped polycrystalline $\mathrm{TiO}_{2}$ for the degradation of chlorpyrifos under UV/solar light. Journal of Molecular Catalysis A: Chemical, 308, 174-181. http://dx.doi.org/10.1016/j.molcata.2009.04.007 
Eaton, A. D., Clesceri, L. S., Rice, E. W., \& Greenberg, A. E. (2005). Standard methods for the examination of water \& waste-water (21 th ed.). Washington, DC: American Public Health Association.

Inan, F., Pala, M., \& Doymaz, I., (2007). Use of ozone in detoxification of aflatoxin $\mathrm{B}_{1}$ in red pepper. Journal of Stored Products Research, 43, 425-429. http://dx.doi.org/10.1016/j.jspr.2006.11.004

Ince, N. H., \& Tezcanlí, G. (2001). Reactive dyestuff degradation by combined sonolysis and ozonation. Dye and Pigments, 49, 145-153. http://dx.doi.org/10.1016/S0143-7208(01)00019-5

Meng, J., Yang, B., Zhang, Y., Dong, \& Shu, X. J. (2010). Heterogeneous ozonation of suspended malathion and chlorpyrifos particles. Chemosphere, 79, 394-400. http://dx.doi.org/10.1016/j.chemosphere.2010.02.008

Pang, Y. L., Abdullah, A. Z., \& Bhatia, S. (2011). Review on sonochemical methods in the presence of catalysts and chemical additives for treatment of organic pollutants in wastewater. Desalination, 277, 1-14. http://dx.doi.org/10.1016/j.desal.2011.04.049

Schneider, K. R., Pierce, R. H., \& Rodrick, G. E. (2003). The degradation of Karenia brevis toxins utilizing ozonated seawater. Harmful Algae, 2, 101-107. http://dx.doi.org/10.1016/S1568-9883(03)00020-9

Schramm, J. D., \& Hua, I. (2001). Ultrasonic irradiation of dichlorvos: decomposition mechanism. Water Reseacrh, 35(3), 665-674. http://dx.doi.org/10.1016/S0043-1354(00)00304-3

Song, W., \& O'Shea, K. E. (2007). Ultrasonically induced degradation of 2-methylisoborneol and geosmin. Water Research, 41, 2672-2678. http://dx.doi.org/10.1016/j.watres.2007.02.041

Steinwandter, H. (1985). Universal $5 \mathrm{~min}$ on-line method for extraction and isolation pesticide residues and industrial chemicals. Fresenius' Journal of Analytical Chemistry, 223, 752-754. http://dx.doi.org/10.1007/BF00489393

Tezcanli, G. G., \& Ince, N. H. (2004). Individual and combined effects of ultrasound, ozone and UV irradiation: a case study with textile dyes. Ultrasonics, 42, 603-609. http://dx.doi.org/10.1016/j.ultras.2004.01.096

Tsuda, T., Kojima, M., Harada, H., Nakajima, A., \& Aoki, S. (1997). Acute toxicity, accumulation and excretion of organophosphorus insecticides and their oxidation products in killifish. Chemosphere, 35, 939-949. http://dx.doi.org/10.1016/S0045-6535(97)00180-X

Wang, J., Pan, Z., Zhang, Z., Zhang, X., Wen, F., Ma, T., ... Kang, P. (2006). Sonocatalytic degradation of methyl parathion in the presence of nanometer and ordinary anatase titanium dioxide catalysts and comparison of

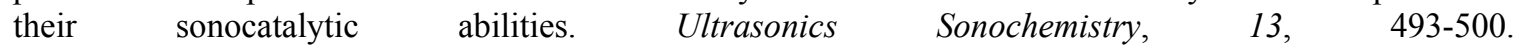
http://dx.doi.org/10.1016/j.ultsonch.2005.11.002

Weavers, L. K., Ling, F. H., \& Hoffmann, M. R. (1998). Aromatic compound degradation in water using a combination of sonolysis and ozonolysis. Environmental Science \& Technology, 32(18), 2727-2733. http://dx.doi.org/10.1021/es970675a

Wenrong, H., \& Haiyan, P. (2002). Decomposed characteristic of azo dyes by ozonization with ultrasonic enhancement. E-Journal of Chinese Science Bulletin, 47, 986-989. http://csb.scichina.com: 8080/ kxtbe/file up/PDF/02ky0986.pdf

Whangchai, K., Uthaibutra, J., Phiyanalinmat, S., Pengphol, S., \& Nomura, N. (2011). Effect of ozone treatment on the reduction of chlorpyrifos residues in fresh lychee fruits. Ozone: Science \& Engineering, 33, 232-235. http://dx.doi.org/10.1080/01919512.2011.554313

Whitacre, D. M. (2012). Reviews of environmental contamination and toxicology 215. London: Springer New York Dordrecht Heidelberg.

Wu, J., Luan, T., Lan, C., Lo, T. W. H., \& Chan, G. Y. S. (2007). Removal of residual pesticides on vegetable using ozonated water. Food Control, 18, 466-472. http://dx.doi.org/10.1016/j.foodcont.2005.12.011

Xiong, Z., Cheng, X., \& Sun, D. (2011). Pretreatment of heterocyclic pesticide wastewater using ultrasonic/ozone combined process. Journal of Environmental Sciences, 23(5), 725-730. http://dx.doi.org/10.1016/S1001-0742(10)60465-2

Yao, J. J., Gao, N. Y., Li, C., \& Xu, B. (2010). Mechanism and kinetics of parathion degradation under ultrasonic irradiation. Journal of Hazardous Materials, 175, 138-145. http://dx.doi.org/10.1016/j.jhazmat.2009.09.140

Yue, W., Yao, P., Wei, Y., \& Mo, H. (2008). Synergetic effect of ozone and ultrasonic radiation on degradation of

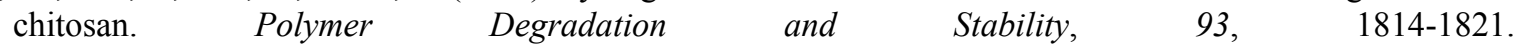
http://dx.doi.org/10.1016/j.polymdegradstab.2008.07.010 